\title{
Effects of some seed disinfectants and a fungicidal ear protection in winter wheat grown from seed heavily infested with Monographella (Gerlachia) nivalis
}

E. Ubels (Research Institute for Plant Protection (IPO), Wageningen, Netherlands)

Accepted: 28 May 1984

\begin{abstract}
Control of Monographella nivalis in winter wheat was investigated by studying the results of different fungicidal seed treatments and of spraying the crop with a fungicide.

Key-words: Monographella nivalis, Gerlachia nivalis, wheat, seed treatment, crop density, head blight, fungicide.
\end{abstract}

Introduction. In the period from 1979 till 1983 Monographella nivalis (stat. con. Gerlachia nivalis) caused a high rate of mortality of seedlings and a lot of head blight in winter wheat in the Netherlands. It was assumed that one of the causal factors was an inadequate seed disinfection resulting from an acquired resistance of the fungus against the fungicidal ingredient fuberidazol (Hartke \& Buchenauer, 1981; Elmsheuser, 1982). This subject was investigated in a series of field experiments which aimed at improving the control of the disease and which included the testing of a direct ear protection with a captafol-containing fungicide. This was done in collaboration between the Plant Protection Service, the Research Institute for Plant Protection and the Government Seed Testing Station at Wageningen and the Research Station for Arable Farming and Field Production of Vegetables at Lelystad, Netherlands.

Experiments and observations. In 1981 three identical split-plot block experiments were carried out in each of which three fuberidazol-containing seed disinfectants (BT, VS, NV; see Fig. 1), two other agents containing guazatine (PN) and methylmercurybenzoate (AA) respectively and an untreated control (OO) were compared in the main plots in four replications. The direct ear protection was performed in the subplots by spraying the crop shortly before flowering with 0.02 $\mathrm{kg} / 100 \mathrm{~m}^{2}$ of a fungicide containing $65 \%$ captafol and $6.25 \%$ triadimefon. This programme was repeated in 1982, but instead of BT we now included an object with a larger quantity (25\% extra) of untreated sowing seed (EZ). The experiments were situated in four locations throughout the country (De Bouwing, Ebelsheerd, Rusthoeve, De Kandelaar; also mentioned in Fig. 1). They were performed with the cultivars Marksman and (in one case) Nautica. The sowing seed used originated from the 1980 and 1981 harvests and was heavily infested (40-57\% of the seeds) 
with $M$. nivalis and slightly with Fusarium spp. In all (sub)plots quantitative assessments were made about crop density before tillering and after flowering, the occurrence of foot rot and head blight mainly caused by $M$. nivalis, leaf and ear condition in general and yield.

Results. 1. Seed treatment especially improved the emergence of the crop and its density before tillering. It did not add much to the ultimate number of ears (higher plant density causing poorer tillering), but it increased the percentage of main stems considerably.

2 . The wheat crops grown from treated seed were not healthier than those from untreated seed. Rather the contrary was the case: the former crops displayed more foot rot and head blight caused by $M$. nivalis and Fusarium spp. and an earlier senescence of the leaves. It is assumed that the seed treatments have indeed improved the chances of survival for the infected seedlings, but in doing so they did the same for the fungi which caused the seedling infection. So the seed treatment may have opposed the natural process of the survival of the fittest. This explanation is supported by the fact that extra untreated seed (EZ) caused the same effects, though to a lesser extent than the chemical seed treatments. Indications for the phenomenon also occur in data presented by Duben \& Fehrmann (1979) and Hewett (1983).

3. Nevertheless in $70 \%$ of all cases the chemical seed treatment resulted in statistically significant $(P \leqslant 0.05)$ yield improvements with an average of $10.3 \mathrm{~kg} / 100 \mathrm{~m}^{2}$.
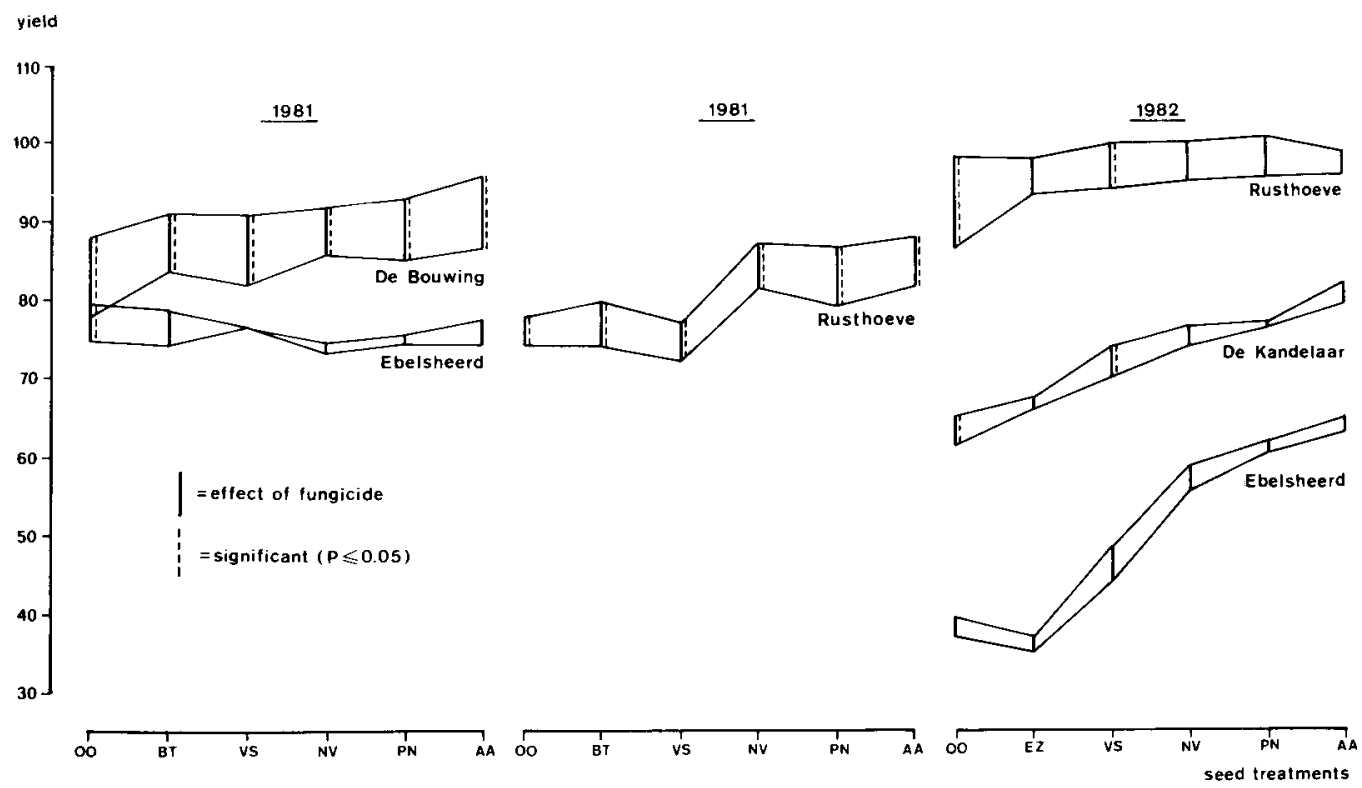

Fig. 1. Mean yield per seed treatment (in $\mathrm{kg} / 100 \mathrm{~m}^{2}$ ) in each of the six experiments, with and without application of a fungicide shortly before flowering. 
This must have been caused by the much higher percentage of main stems with their better productivity and partly by a slight increase of the total number of ears. Improvement of crop density and yield by seed treatment was by far the best in two experiments in which the crops suffered seriously from frost (viz. De Kandelaar and Ebelsheerd in 1982; see Fig. 1). In one experiment seed treatment did not increase the yields at all (Ebelsheerd 1981). The effects of extra seed (EZ) on the yield were less important than those of the chemical seed treatments.

4. The disinfectant containing both fuberidazol and sodium dimethyldithiocarbamate (NV) and those containing guazatine and methylmercurybenzoate respectively (PN and AA) were found to have by far the best effects on crop density and yield. Under normal conditions these three agents were about equally effective; only under very bad winter conditions methylmercurybenzoate acted best.

5. Of the fuberidazol-containing agents those which also contain another ingredient active against $M$. nivalis (viz NV and BT with sodium dimethyldithiocarbamate and triadimenol respectively) had significantly better results than an agent containing fuberidazol and a fungicide not active against this fungus (viz VS with quintozene). Moreover the agents containing the systemic fuberidazol were certainly not more active than those with the non-systemic ingredients guazatine and methylmercurybenzoate. These results point to a reduced sensitivity of $M$. nivalis to fuberidazol in the two lots of sowing seed used for these experiments.

6. The fungicide applied shorthly before flowering prolonged the green condition of leaves and ears, it reduced the ear attack by $M$. nivalis and Fusarium spp. by about one third on an average and resulted in yield improvements of $4.6 \mathrm{~kg} / 100 \mathrm{~m}^{2}$ on an average. These yield improvements, however, were seldom significant and paying when the production level was lower than $80 \mathrm{~kg} / 100 \mathrm{~m}^{2}$, but they were nearly always both significant $(P \leqslant 0.05)$ and paying when the production level was higher.

\section{References}

Duben, J. \& H. Fehrmann. 1979. Vorkommen und Pathogenität von Fusariumarten an Winterweizen in der Bundesrepublik Deutschland. II. Vergleich der Pathogenität als Erreger von Keimlings-. Halmbasis-und Ahrenkrankheiten. Zeitschrift für Pflanzenkrankheiten und Pflanzenschutz 86: 705-728.

Elmsheuser. H., 1982. Bekämpfung von Schneeschimmel mit systemisch wirksamen Beizmitteln. Gesunde Pflanzen 34: 286-289

Hartke, S. \& H. Buchenauer, 1981. Untersuchungen zur Resistenz von Gerlachia nivalis gegenüber Wirkstoffen in Hg-freien Saatgutbehandlungsmitteln. Mitteilungen der Biologische Bundesanstalt für Land- und Forstwirtschaft, Berlin/Dahlem, Heft 203: 240-241.

Hewett, P. D., 1983. Seed-borne Gerlachia nivalis (Fusarium nivale) and reduced establishment of winter wheat. Transactions British Mycological Society 80: 185-186.

This synopsis is based on a report entitled 'Effecten van enkele zaadontsmettingsmiddelen en aarbescherming met een fungicide in wintertarwe uit zwaar met Monographella (Gerlachia) nivalis besmet zaaizaad', Research Institute for Plant Protection (IPO), Wageningen, Netherlands, 1984. iii +29 pp., 3 figs, 8 tables, 25 refs. Dutch; English captions to figures and tables.

Available as paper copy (order R010P, $f 20$ including postage) or microfiche (order R010M, f 12.50 including postage) at: NARD, clo Pudoc, P.O. Box 4, 6700 AA Wageningen, Netherlands (telex 45015 blhwg $\mathrm{nl}$ ). 